\title{
Oxidation and photo-induced oxidation of glucose at a polyaniline film modified by copper particles
}

\author{
Sinéad T. Farrell, Carmel B. Breslin*,1 \\ Department of Chemistry, National University of Ireland Maynooth, Maynooth, Co. Kildare, Ireland \\ Received 22 January 2004; received in revised form 23 April 2004; accepted 4 May 2004
}

Available online 9 June 2004

\begin{abstract}
The oxidation and photo-induced oxidation of glucose at a copper-dispersed polyaniline film was studied in an alkaline hydroxide solution. It was found that the copper-dispersed polyaniline electrode was capable of oxidizing glucose at potentials between $0.2 \mathrm{and} 0.75 \mathrm{~V} /(\mathrm{Ag} \mid \mathrm{AgCl})$, with the rate of oxidation being higher than that observed at a bulk copper electrode. On irradiation of the composite with polychromatic UV light, a further increase in the rate of the glucose oxidation reaction was observed. Formate was identified as the main product of the glucose oxidation reaction under both light and dark conditions using ${ }^{1} \mathrm{H}$ NMR spectrometry. This suggests that illumination does not alter significantly the reaction pathway.

(C) 2004 Elsevier Ltd. All rights reserved.
\end{abstract}

Keywords: Glucose; Polyaniline; Copper; Oxidation; Photo-oxidation

\section{Introduction}

In recent years there have been many reported studies on the incorporation of metal particles within a conducting polymer matrix, such as polyaniline or polypyrrole [1-7]. This incorporation can be achieved readily by the reduction of the appropriate metal salt at the conducting polymer interface. The interest in these materials lies in the fact that they are promising new materials in the fields of catalysis and electrocatalysis. For example, the incorporation of noble metals within the porous polymer matrix produces a highly dispersed noble metal catalyst with a greater surface area and a much lower probability of agglomeration of the metal particles. There is also evidence in the literature to show that the poisoning of these incorporated catalytic particles by strongly adsorbed species, such as CO, is significantly less than that observed with their bulk counterparts [8-10].

In particular, there are a number of reports on the incorporation of noble metal particles in a polyaniline or polypyrrole matrix and the catalytic oxidation of carbohydrate molecules, such as glucose, at these particles [11,12].

\footnotetext{
* Corresponding author. Tel.: +353-1-7083677; fax: +353-1-7083815.

E-mail address: cb.breslin@may.ie (C.B. Breslin).

${ }^{1}$ ISE member.
}

For example, Becerik et al. [4,12] have shown that more efficient oxidation of D-glucose occurs at palladium- or platinum-dispersed polypyrrole electrodes than at pure palladium or platinum substrates. Likewise, Guascito et al. [3] have observed the oxidation of glucose in an alkaline $\mathrm{NaOH}$ solution at a copper-dispersed poly-3-methylthiophene substrate.

The oxidation of glucose in an alkaline solution at copper or copper-containing alloys is well known, although the mechanism by which this oxidation proceeds remains somewhat controversial [13-19]. Johnson and co-workers [14,15] in studying the oxidation of glucose at a number of copper alloys have explained the enhanced oxidation at a $\mathrm{Mn}_{5} \mathrm{Cu}_{95}$ in terms of the Mn sites functioning as Lewis acid sites for adsorption of the polar glucose molecule, while they have interpreted the oxidation at a $\mathrm{Ni}_{10} \mathrm{Cu}_{90}$ alloy in terms of a redox-mediated mechanism. Marioli and Kuwana [20] have identified the interaction of the glucose with the oxide/hydroxide layer as an important step in the subsequent oxidation of the molecule. This interaction is initially observed with the $\mathrm{Cu}(\mathrm{I})$ oxidation state, although interaction may also occur with the $\mathrm{Cu}(\mathrm{II})$ state once it is formed.

In this paper, results are presented and discussed on the oxidation and photo-induced oxidation of glucose at a copper-dispersed polyaniline film. To the best of our 
knowledge, there are no reports in the literature in which the photo-induced oxidation of glucose has been observed at either a copper-dispersed polymer or a pure copper substrate.

\section{Experimental}

Electrodes were prepared from pure platinum $(99.999+\%)$ and pure copper $(99.999+\%)$ rods. These rods were set with epoxy resin in a Teflon holder and electrical contact achieved by means of a copper wire attached to the base of the metal sample with conducting silver-loaded resin. Prior to each test the samples were polished to a smooth surface finish, using successively finer grades of SiC paper, and rinsed with distilled water.

The electrochemical cell was made of Teflon with a quartz window in the base to allow irradiation of the test electrodes. High-density graphite rods were used as the auxiliary electrodes and a silver-silver chloride electrode was used as the reference electrode. All potentials quoted are relative to this electrode. The illumination source was a $300 \mathrm{~W}$ Xenon arc lamp (Oriel Model 6258). The light was passed through a water cooler to remove infrared radiation. The beam was then passed through a series of filters, lens and mirrors and focused on the stage to illuminate the surface of the exposed electrode. The intensity of the light entering the cell was measured as $200 \mathrm{~mW} / \mathrm{cm}^{2}$ for unfiltered irradiation (200-900 nm) using a Spectra-Physics CW Laser Power Meter Model 407A. A maximum temperature rise of $1.9^{\circ} \mathrm{C}$ was recorded over a 30 -min illumination period with this polychromatic illumination procedure.

The electrolytes were prepared using analytical grade reagents and distilled water. The polyaniline films were prepared using $1.0 \mathrm{~mol} \mathrm{dm}^{-3} \mathrm{H}_{2} \mathrm{SO}_{4}$ and $0.1 \mathrm{~mol} \mathrm{dm}^{-3}$ aniline. Prior to use, aniline was distilled and stored in the dark under an atmosphere of nitrogen. Copper was deposited at the polyaniline film from a $0.02 \mathrm{~mol} \mathrm{dm}^{-3} \mathrm{CuSO}_{4}$ solution. An alkaline, $0.15 \mathrm{~mol} \mathrm{dm}^{-3} \mathrm{NaOH}$ solution, to which additions of glucose were made, was used in the electrocatalysis studies.

An analytical method was used to quantify the amount of glucose electro-oxidized. This was achieved using the Benedict's solution [21] $\left(1.1 \mathrm{~mol} \mathrm{dm}^{-3}\right.$ sodium carbonate, $0.7 \mathrm{~mol} \mathrm{dm}^{-3}$ sodium citrate dihydrate and $0.7 \mathrm{~mol} \mathrm{dm}^{-3}$ copper sulphate pentahydrate). The Benedict's solution contains a $\mathrm{Cu}^{2+}$-citrate complex, which is blue in colour and has an absorbance at $739 \mathrm{~nm}$. Once heated this complex will re- act with the aldehyde functional group of glucose becoming oxidized to a carboxylic acid group as shown in Scheme 1. Accordingly, the absorbance at $739 \mathrm{~nm}$ can be equated with the concentration of glucose.

The electrochemical measurements were carried out using a Solartron EI 1287 potentiostat. Cyclic voltammograms were recorded at a scan rate of $50 \mathrm{mV} \mathrm{s}^{-1}$. Scanning electron micrographs and energy-dispersive X-ray analyses were recorded on a Hitachi S-4700 cold cathode field emission SEM using a secondary electron detector at an accelerating voltage of $15 \mathrm{kV}$. The X-ray spectra were obtained using an Oxford Instruments Inca Energy EDX detector attached to the SEM. The samples were gold coated prior to imaging using an Emitech K550 sputter coater. NMR spectra were recorded on a $300 \mathrm{MHz}$ Bruker spectrometer. DMSO was used as the internal standard $(2.51 \mathrm{ppm})$ and the residual deuterated solvent was $\mathrm{D}_{2} \mathrm{O}$.

\section{Results and discussion}

\subsection{Preparation and electrochemical characterization of the modified electrode towards glucose oxidation}

The copper-dispersed polyaniline electrodes were synthesized by depositing copper at polyaniline prepared electrochemically at platinum. The pure polyaniline was electrosynthesized by cycling the electrode in a $0.1 \mathrm{~mol} \mathrm{dm}^{-3}$ $\mathrm{H}_{2} \mathrm{SO}_{4}$ solution containing $0.1 \mathrm{~mol} \mathrm{dm}^{-3}$ aniline. A preliminary cycle to $0.9 \mathrm{~V}$ was used to initiate radical cation formation, followed by repeated cycling between -0.2 and a lower potential of $0.75 \mathrm{~V} /(\mathrm{Ag} \mid \mathrm{AgCl})$ to sustain polymer growth without over-oxidation. This procedure, in which oxidation of polyaniline to the higher pernigraniline state was avoided, gave rise to the growth of pure polyaniline layers free from any degradation products. The thickness of these films was estimated as $125 \pm 10 \mathrm{~nm}$ based on the $500 \mathrm{C} \mathrm{cm}^{-3}$ conversion factor [22]. The copper-polyaniline composites were then prepared by depositing copper from $20 \mathrm{mmol} \mathrm{dm}^{-3} \mathrm{CuSO}_{4}$ with $0.1 \mathrm{~mol} \mathrm{dm}^{-3} \mathrm{H}_{2} \mathrm{SO}_{4}$ at an applied potential of $-0.175 \mathrm{~V} /(\mathrm{Ag} \mid \mathrm{AgCl})$ for $30 \mathrm{~min}$. A total weight of $50 \pm 2.0 \mu \mathrm{g} \mathrm{cm}^{-2}$ of copper was deposited at each polyaniline electrode. Using scanning electron microscopy and energy-dispersive X-ray analyses, the deposited copper was found to disperse at the polyaniline film as particles with radii between 100 and $150 \mathrm{~nm}$. This is in agreement with several previous studies [1-3,11].

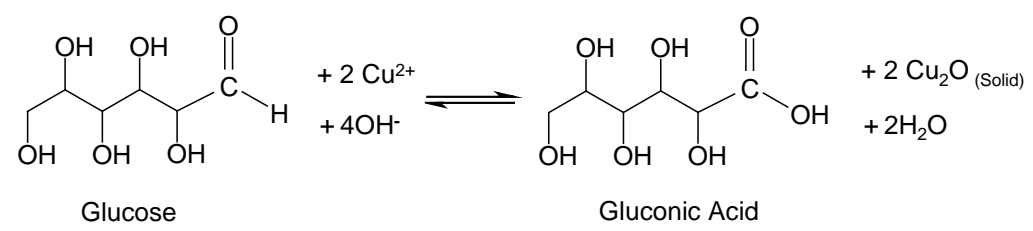




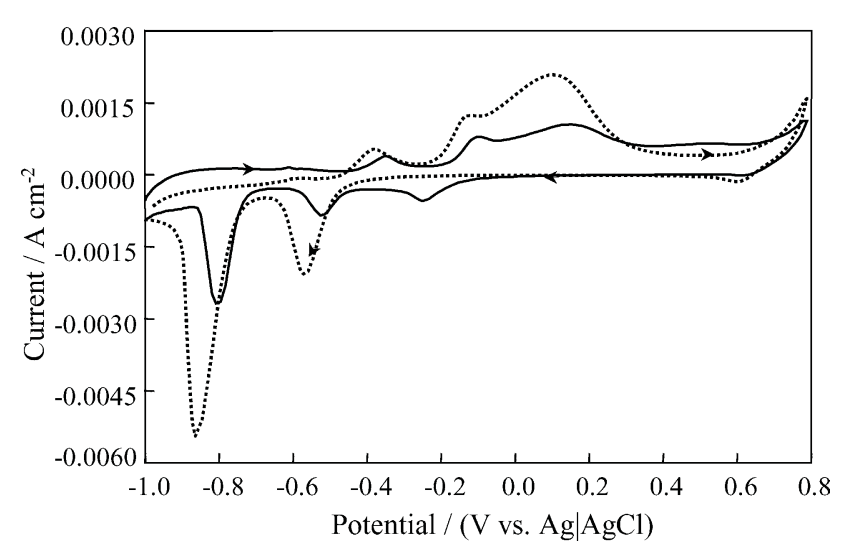

Fig. 1. Cyclic voltammograms (10th cycle) at a (...) copper and a (-) copper-modified polyaniline electrode in $0.15 \mathrm{~mol} \mathrm{dm}^{-3} \mathrm{NaOH}$ between -1.0 and $0.79 \mathrm{~V} /(\mathrm{Ag} \mid \mathrm{AgCl})$.

In Fig. 1, the cyclic voltammograms of pure copper and a copper-polyaniline composite are compared for data recorded between the potential limits of -1.0 to $0.79 \mathrm{~V} /(\mathrm{Ag} \mid \mathrm{AgCl})$. In both cases the data were recorded in $0.15 \mathrm{~mol} \mathrm{dm}^{-3} \mathrm{NaOH}$. Both the bulk copper and the copper-polyaniline electrodes display the various well-defined characteristic copper oxide/hydroxide formation peaks [23-25]. In particular, the oxidation peak at $-0.38 \mathrm{~V} /(\mathrm{Ag} \mid \mathrm{AgCl})$ represents the conversion of $\mathrm{Cu}$ to $\mathrm{Cu}(\mathrm{I})$. The oxidation peak at $-0.124 \mathrm{~V} /(\mathrm{Ag} \mid \mathrm{AgCl})$ represents the formation of $\mathrm{Cu}(\mathrm{II})$ species due to oxidation of metallic $\mathrm{Cu}$ to $\mathrm{Cu}(\mathrm{II})$ and $\mathrm{Cu}(\mathrm{I})$ to $\mathrm{Cu}(\mathrm{II})$. The large wave centred at a peak potential of $0.11 \mathrm{~V} /(\mathrm{Ag} \mid \mathrm{AgCl})$ can be associated with the formation of soluble species, such as $\mathrm{HCuO}_{2}{ }^{-}$, from the oxidation of $\mathrm{Cu}$, while the current increase at potentials in the vicinity of $0.55 \mathrm{~V} /(\mathrm{Ag} \mid \mathrm{AgCl})$ has previously been attributed to the formation of $\mathrm{Cu}$ (III) species, which are easily formed in highly alkaline electrolytes [23]. Examination of the reverse scan reveals, initially a small cathodic peak at $0.6 \mathrm{~V} /(\mathrm{Ag} \mid \mathrm{AgCl})$, which has been attributed to the reduction of $\mathrm{Cu}(\mathrm{III})$ to $\mathrm{Cu}(\mathrm{II})$ [23]. The symmetric cathodic peaks at -0.57 and $-0.86 \mathrm{~V} /(\mathrm{Ag} \mid \mathrm{AgCl})$ are due to the transition of $\mathrm{Cu}(\mathrm{II})$ to $\mathrm{Cu}(\mathrm{I})$ and $\mathrm{Cu}(\mathrm{I})$ to $\mathrm{Cu}$, respectively. Very similar responses are observed at the copper-modified polymer electrode. But, the peak potentials observed at the composite are slightly shifted in the anodic direction. It is also seen that the composite gives much lower currents, which is connected with the fact that the composite has a lower concentration of copper than the bulk electrode.

In Fig. 2, the cyclic voltammograms (10th cycle) recorded between the potential limits of -0.2 and $0.79 \mathrm{~V} /(\mathrm{Ag} \mid \mathrm{AgCl})$ for pure copper and the copper-polyaniline composite in $0.15 \mathrm{~mol} \mathrm{dm}^{-3} \mathrm{NaOH}$ and in $0.15 \mathrm{~mol} \mathrm{dm}^{-3} \mathrm{NaOH}$ with the addition of $3.8 \mathrm{mmol} \mathrm{dm}^{-3}$ glucose are shown. In these figures, the currents are normalized to the surface area of copper. This was achieved by assuming that the magnitude of the charge under the copper oxide reduction peaks, Fig. 1, is an approximate indication of the amount of electroactive copper. However, it should be noted that the oxidation currents

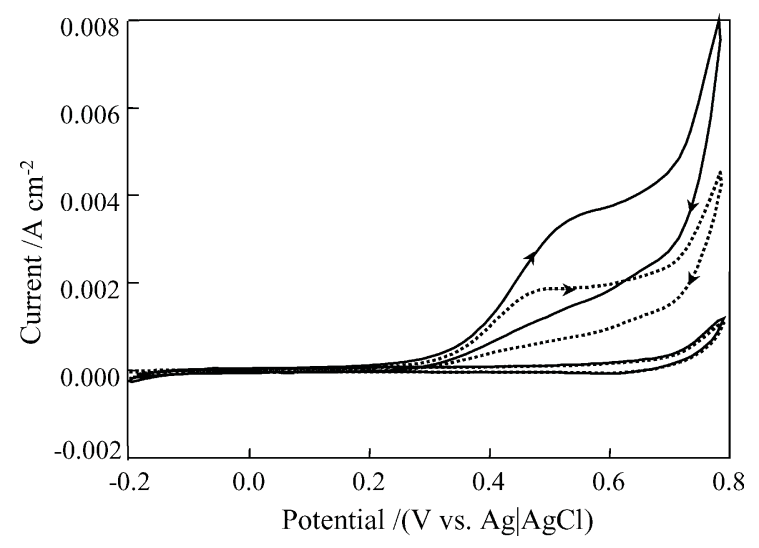

Fig. 2. Cyclic voltammograms (10th cycle) of (...) bulk copper and (-) copper-modified polyaniline electrode in $3.8 \mathrm{mmol} \mathrm{dm}^{-3}$ glucose in $0.15 \mathrm{~mol} \mathrm{dm}^{-3} \mathrm{NaOH}$ with currents normalized to surface copper load. Also shown are background voltammograms (lower current traces) before addition of glucose $(. .$.$) bulk copper and (-)$ copper-modified polyaniline.

were in fact higher for the composite than the bulk electrode before any normalization. In the absence of glucose, the currents remain low until potentials exceeding $0.7 \mathrm{~V} /(\mathrm{Ag} \mid \mathrm{AgCl})$ are applied; there is no evidence of the oxidation of copper, as seen in Fig. 1, because of the higher switching potential of $-0.2 \mathrm{~V} /(\mathrm{Ag} \mid \mathrm{AgCl})$, or of the electroactivity of polyaniline, as it is well known that polyaniline loses electroactivity in alkaline media $[11,26]$. In the presence of glucose, a single forward oxidative wave, corresponding to the irreversible glucose oxidation reaction is observed for both electrodes. An increase in the oxidation currents is observed at approximately $0.20 \mathrm{~V} /(\mathrm{Ag} \mid \mathrm{AgCl})$, marking the onset of glucose oxidation. These currents continue to increase up to a potential of $0.65 \mathrm{~V} /(\mathrm{Ag} \mid \mathrm{AgCl})$. This agrees with the proposed involvement of copper (II) and copper (III) surface species in the oxidation of glucose, as $\mathrm{Cu}(\mathrm{II})$ and $\mathrm{Cu}(\mathrm{III})$ species are present in this potential range [20]. On the reverse cycle, there is further oxidation of glucose. The bulk copper electrode shows a peak in the oxidation wave at approximately $0.50 \mathrm{~V} /(\mathrm{Ag} \mid \mathrm{AgCl})$, while the composite electrode shows an oxidation peak centred at approximately $0.57 \mathrm{~V} /(\mathrm{Ag} \mid \mathrm{AgCl})$. However, the oxidation currents at the composite are over twice that at the bulk electrode. This indicates greater catalytic efficiency at the composite electrode.

\subsection{Photo-induced oxidation of glucose at the composite electrode}

In Fig. 3(a) and (b), the influence of illumination on the electrocatalytic activity of copper and the copper-polyaniline composite in $0.15 \mathrm{~mol} \mathrm{dm}^{-3} \mathrm{NaOH}$ and $3.8 \mathrm{mmol} \mathrm{dm}^{-3}$ glucose is shown, respectively. Three traces are presented: one corresponding to the cyclic voltammogram recorded under illumination conditions but in the absence of glucose, one corresponding to the data recorded in the glucose-containing solution under dark conditions and the third trace gives the 
voltammograms recorded under continuous illumination conditions. Much higher oxidation currents are observed with both the composite and the bulk electrode upon illumination. The forward oxidation current is increased by a factor of $89 \%$ for the composite electrode and a factor of $47 \%$ for the bulk copper electrode with illumination. This clearly shows that the activity of the composite electrode is enhanced to a greater extent with illumination; for example, the forward oxidation current of the composite is 2.6 times greater than that of the bulk copper electrode under illumination conditions.

To ensure that the oxidation currents observed under illumination conditions were connected with the oxidation of glucose, the concentration of glucose was followed analytically under dark and light conditions. For the purpose of these experiments, a $7.60 \mathrm{mmol} \mathrm{dm}^{-3}$ glucose solution was oxidized at a constant applied potential of $0.5 \mathrm{~V} /(\mathrm{Ag} \mid \mathrm{AgCl})$ for a 30-min period under dark and light conditions. Upon analysis, the concentrations of glucose were determined as $7.20 \pm 0.09$ and $6.85 \pm 0.08 \mathrm{mmol} \mathrm{dm}^{-3}$ for the dark and light experiments, respectively, showing a near two-fold increase in the amount of glucose oxidized under illumination conditions. Interestingly, the ratio of the charges passed, $Q_{\text {light }} / Q_{\text {dark }}$ was $1.8 \pm 0.1$, which correlates well with the changes in the concentrations.

The influence of glucose concentration on the oxidation reaction at the composite electrode was examined under dark and light conditions. Glucose concentrations were varied from 1.0 to $8.5 \mathrm{mmol} \mathrm{dm}^{-3}$ and the oxidation currents were recorded at a constant applied potential at $0.60 \mathrm{~V} /(\mathrm{Ag} \mid \mathrm{AgCl})$. At this potential, the oxidation reaction occurs efficiently as shown in Fig. 3(b). These currents are plotted as a function of glucose concentration in Fig. 4. The plot shows two traces, for near-steady-state currents recorded under dark (following 300 s) and under UV illumination conditions. In the case of the illumination experiments, the data were recorded following the $300 \mathrm{~s}$ under dark conditions, and the photocurrent was measured following an additional $200 \mathrm{~s}$. Interestingly, these traces are not parallel, with the slopes differing by a factor of 1.5. This indicates that the photo-induced reactions occur to a greater extent at the higher glucose concentrations.

The oxidation and photo-induced oxidation reactions were also found to depend on the copper loading. A typical plot showing the steady-state oxidation current measured at $0.65 \mathrm{~V} /(\mathrm{Ag} \mid \mathrm{AgCl})$ under dark and illumination conditions in a $3.8 \mathrm{mmol} \mathrm{dm}^{-3}$ glucose solution are shown in Fig. 5. Both traces clearly show that the oxidation currents increase rapidly up to loadings of approximately $20 \mu \mathrm{g} \mathrm{cm}^{-2}$. At higher copper loadings, the oxidation currents of both the light and dark experiments increase at a much slower rate, attaining almost steady-state conditions at loadings above $40 \mu \mathrm{g} \mathrm{cm}^{-2}$. However, it is seen that the oxidation currents are higher under illumination conditions for all copper loadings, with the difference in the dark and light currents being near constant for copper loadings exceeding $40 \mu \mathrm{g} \mathrm{cm}^{-2}$.
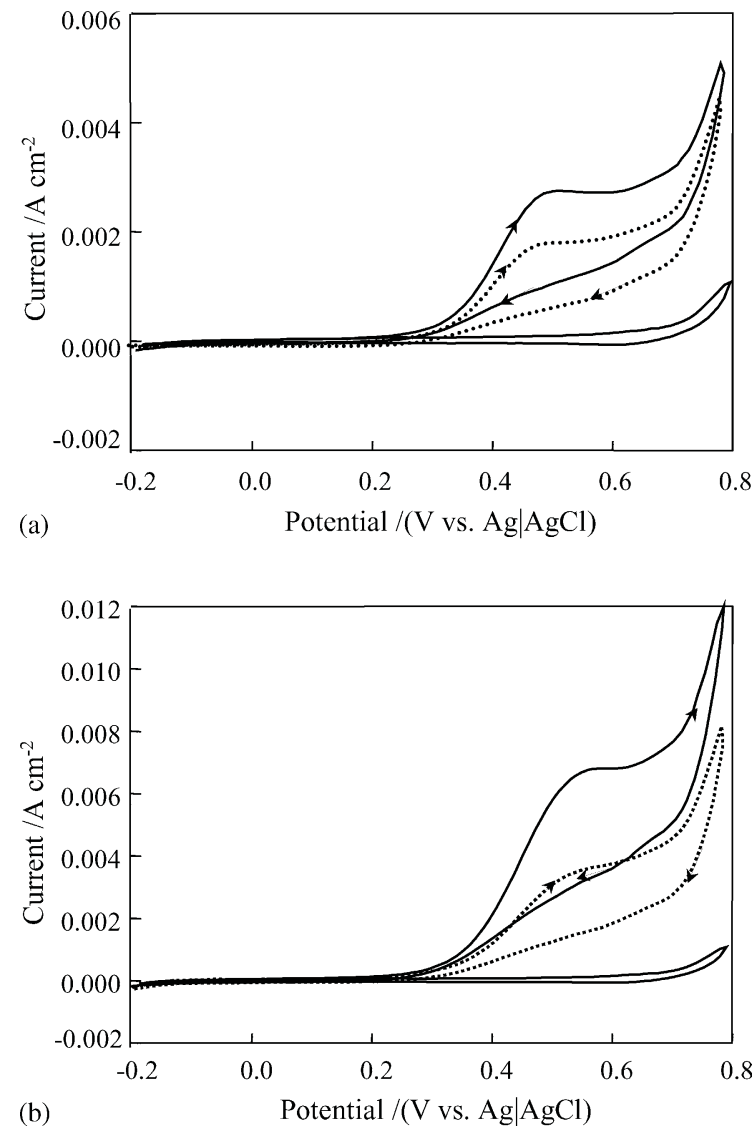

Fig. 3. Cyclic voltammogram (10th cycle) of $3.8 \mathrm{mmol} \mathrm{dm}^{-3}$ glucose oxidation in $0.15 \mathrm{~mol} \mathrm{dm}^{-3} \mathrm{NaOH}$ at (a) bulk copper and (b) copper-modified polyaniline electrode under $(-)$ illuminated and $(. .$.$) dark conditions.$ Background response under illumination before addition of glucose is also shown (low current trace).

In order to rule out the possibility that the glucose is oxidized by dissolved copper from the composite, the oxidation of glucose in a $0.15 \mathrm{~mol} \mathrm{dm}^{-3} \mathrm{NaOH}$ solution with the addition of $10 \mathrm{mmol} \mathrm{dm}^{-3} \mathrm{CuSO}_{4}$ was studied. Identical cyclic voltammograms were recorded in the presence and absence

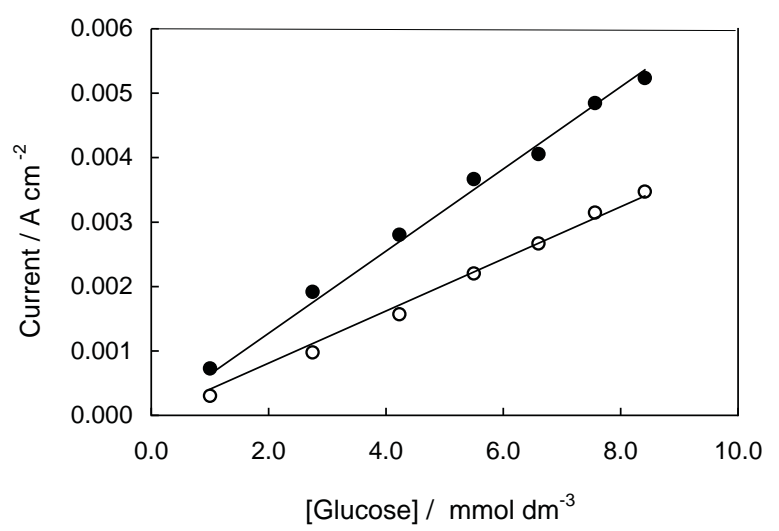

Fig. 4. Steady-state glucose oxidation currents at an applied potential of $0.6 \mathrm{~V} /(\mathrm{Ag} \mid \mathrm{AgCl})$ at the composite electrode under $(\bigcirc)$ dark and illuminated conditions. 


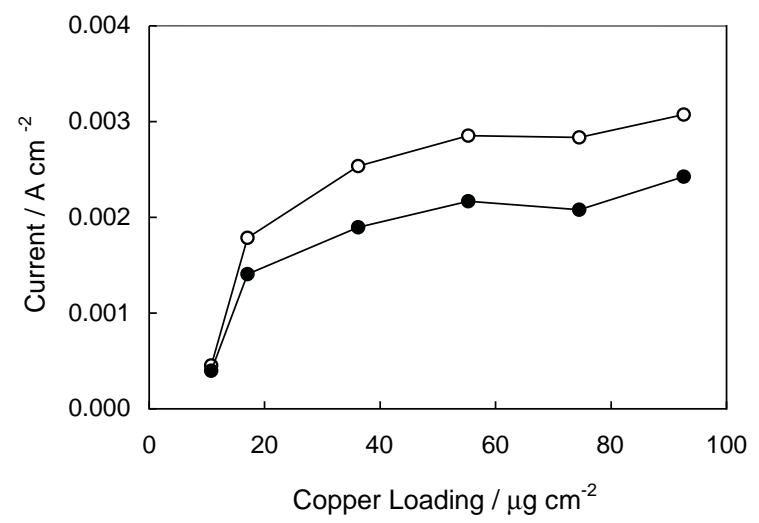

Fig. 5. Effect of copper loading on the rate of glucose oxidation in $3.8 \mathrm{mmol} \mathrm{dm}^{-3}$ glucose in $0.15 \mathrm{~mol} \mathrm{dm}^{-3} \mathrm{NaOH}$ under $(\bigcirc)$ dark and $(\bigcirc)$ illuminated conditions.

of the dissolved copper, indicating that any copper dissolved from the composite would have little role in oxidizing the glucose under these conditions.

In addition, heating of the solution during illumination was discounted as being responsible for the photo-induced oxidation of glucose. An Arrhenius-type plot was constructed for the oxidation of $3.8 \mathrm{mmol} \mathrm{dm}^{-3}$ glucose in the temperature interval $0.0-40^{\circ} \mathrm{C}$. A linear plot was obtained between the logarithm of the oxidation current and the inverse of temperature, giving an activation energy of $39.23 \mathrm{~kJ} \mathrm{~mol}^{-1}$. This value agrees well with previous values reported by Bercerik and Kadirgan [27] of $38.07 \mathrm{~kJ} \mathrm{~mol}^{-1}$ for the electrocatalytic oxidation of glucose. However, in order to generate the oxidation currents observed during illumination, the temperature of the dark solution would have to be maintained at values in excess of $50^{\circ} \mathrm{C}$. Using a copper thermocouple, the maximum temperature rise was recorded as $1.5^{\circ} \mathrm{C}$ following illumination for a 20 -min period. Consequently, the enhanced oxidation of glucose observed during illumination cannot be explained in terms of heating during illumination.

In order to obtain information on the products generated during the oxidation of glucose, ${ }^{1} \mathrm{H}$ NMR spectrometry was employed. For these measurements the concentration of glu- cose was increased to $30 \mathrm{mmol} \mathrm{dm}^{-3}$. The solution of glucose was oxidized under dark and illumination conditions at $0.65 \mathrm{~V} /(\mathrm{Ag} \mid \mathrm{AgCl})$ for a 10 -h period and then analysed. In Fig. 6, the ${ }^{1} \mathrm{H}$ NMR spectra of a solution of glucose before oxidation and solutions electrolysed under dark and light conditions are shown, marked as (a), (b) and (c), respectively. For the starting material, the expected absorptions for glucose in the 3.0-3.8 ppm region are seen. As the concentration of glucose is relatively high, the electrolysis period gives rise to only small decreases in the concentration of glucose; with the concentration falling to lower values under illumination conditions. The peak centred at $8.2 \mathrm{ppm}$, which is only observed following electrolysis, is attributed to formate and has been observed previously by Luo and Baldwin [19]. This formation of formate indicates that complete $\mathrm{C}-\mathrm{C}$ bond cleavage occurs. This is also in agreement with the findings of Marioli and Kuwana [20] who concluded that the oxidation of glucose may proceed beyond the formation of gluconic or glucuronic acids to give lower molecular weight products and fragmentation of the carbohydrate carbon skeleton. There may be some evidence for the formation of six carbon derivatives, form the additional absorptions in the 3.0-3.8 ppm region following electrolysis (Fig. 6(b) and (c)). But it is impossible to identify these products as the signals overlap with the absorptions of glucose to give complex spectra. In addition, the spectra obtained after electrolysis in the dark and light appear somewhat different because the concentration of glucose is much lower after the 10-h electrolysis period with illumination. However, regardless of the electrolysis period, no new absorptions were observed in the 6.0-7.0 ppm region which would indicate the formation of glucuronic acid, indicating that the major product is formate, in agreement with Luo and Baldwin [19].

But, perhaps the most important conclusion to be drawn from these data is that the same formate oxidation products are produced, with complete fragmentation of the carbon skeleton, under dark and illumination conditions. This, in turn, indicates that illumination does not alter significantly the reaction adducts or intermediates, but alters the nature of the surface of the catalyst to give much higher rates of oxidation of glucose.

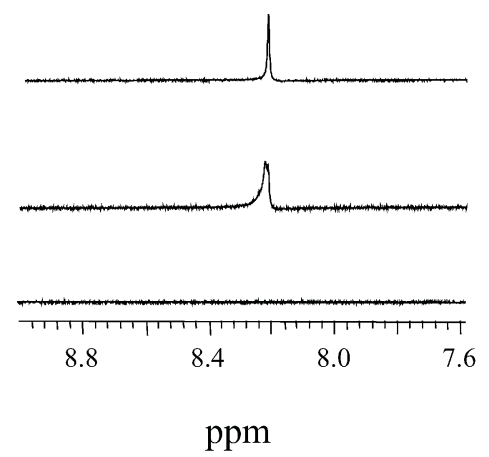

(c)

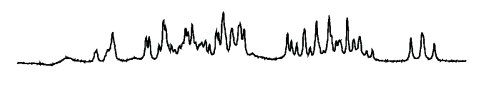

(b)

(a)

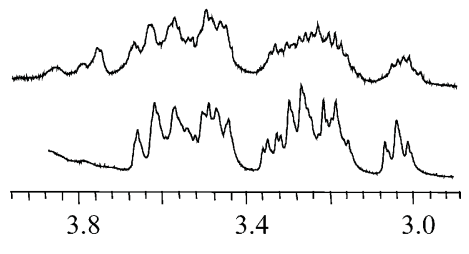

ppm

Fig. 6. ${ }^{1} \mathrm{H}$ NMR spectra of $30 \mathrm{mmol} \mathrm{dm}^{-3}$ glucose solution (a) prior to electrolysis and after a 10 -h electrolysis period at $0.65 \mathrm{~V} /(\mathrm{Ag} \mid \mathrm{AgCl})$ at the copper-polyaniline composite under (b) dark and (c) illumination conditions. 
Table 1

Glucose, fructose, sorbitol and glycine oxidation charges shown as a function of light and dark conditions at copper and gold electrodes in 0.15 mol dm ${ }^{-3}$ $\mathrm{NaOH}$

\begin{tabular}{|c|c|c|c|c|c|c|}
\hline \multirow[t]{3}{*}{ Compound } & \multicolumn{3}{|l|}{ Copper } & \multicolumn{3}{|l|}{ Gold } \\
\hline & \multirow[t]{2}{*}{ Concentration $\left(\mathrm{mmol} \mathrm{dm}{ }^{-3}\right.$ ) } & \multicolumn{2}{|c|}{ Charge $\left(\mathrm{C} \mathrm{cm}^{-2}\right)$} & \multirow[t]{2}{*}{ Concentration $\left(\mathrm{mmol} \mathrm{dm}^{-3}\right)$} & \multicolumn{2}{|c|}{ Charge $\left(\mathrm{C} \mathrm{cm}^{-2}\right)$} \\
\hline & & Dark & Illumination & & Dark & Illumination \\
\hline Glucose & 3.8 & 0.029 & 0.043 & 10.0 & 0.038 & 0.038 \\
\hline Fructose & 10.0 & 0.167 & 0.212 & 10.0 & 0.075 & 0.077 \\
\hline Sorbitol & 10.0 & 0.185 & 0.245 & 10.0 & 0.053 & 0.054 \\
\hline
\end{tabular}

Furthermore, this photo-induced oxidation is not restricted to glucose. The rate of oxidation of fructose, sorbitol and glycine was observed to be much higher under illumination conditions at the composite and at pure copper. Typical data comparing the oxidative charge passed during oxidation of the analyte at pure copper on polarizing the electrode between -0.2 and $0.8 \mathrm{~V}$ under dark and light conditions are presented in Table 1. In each case, the charge recorded under illumination conditions is considerably higher than that observed under dark conditions, with a $60 \%$ increase in the charge for oxidation of glycine under illumination conditions. It is interesting to compare these results with similar experiments recorded with a gold electrode. Again, the charges computed for oxidation of the analytes on polarizing the gold electrode between -0.6 and $1.0 \mathrm{~V}$ are presented in Table 1. However, in this case the charges recorded under dark and light conditions are identical, showing that illumination has no effect on the rate of these oxidation reactions at a gold interface.

This photo-induced oxidation of glucose observed at both copper and the copper-dispersed electrodes appears to be connected with the properties of the copper oxides, as these reactions are not induced at the gold interface. According to the model proposed by Marioli and Kuwana [20] for the oxidation of glucose, the oxidation is initiated by the deprotonation of the carbohydrate and isomerization to the enediol form followed by adsorption onto the electrode surface. Carbohydrate is then oxidized by the $\mathrm{Cu}(\mathrm{II})$ and $\mathrm{Cu}(\mathrm{III})$ surface states. It is difficult to see how illumination could alter the adsorption step. Indeed, if this occurred, then a similar increase in the rate of oxidation should be observed at the gold electrode, and this is not the case. Also, illumination seems to have little influence on the pathway of the reaction, with the same products being formed under dark and light conditions (Fig. 6). One possible explanation to account for these observations may involve the semi-conducting properties of the copper oxides. It is widely accepted that the passive films formed on copper in alkaline solutions, although complex in nature, consist of an overall duplex structure, with an inner layer of $\mathrm{Cu}_{2} \mathrm{O}$ and an outer layer of $\mathrm{CuO}$, followed by $\mathrm{Cu}(\mathrm{OH})_{2}$ at higher applied potentials [28,29]. Both $\mathrm{Cu}_{2} \mathrm{O}$ and $\mathrm{CuO}$ are well-known p-type semiconductors, with the defects arising from cation vacancies in the oxide lattice. The bandgap energy of $\mathrm{Cu}_{2} \mathrm{O}$ is reported to be $2.1 \mathrm{eV}$, while that of $\mathrm{CuO}$ is $1.7 \mathrm{eV}$ [30], although values as low as $0.6 \mathrm{eV}$ [31] have been reported. On illumination, electronic excitations can occur in both oxide phases. However, since the bandgap energy of $\mathrm{CuO}$ is considerably smaller than that of $\mathrm{Cu}_{2} \mathrm{O}$, it is likely that the photo-induced processes will arise from transitions within the $\mathrm{Cu}_{2} \mathrm{O}$ phase, as electron-hole recombination is the likely reaction for the low bandgap $\mathrm{CuO}$. The electrons and holes are swept in different directions depending on whether the semi-conducting electrode is subjected to anodic or cathodic bias, and thus the interfacial reactions can be either oxidative or reductive in nature.

The influence of applied potential on the photocurrent response of the composite polarized in $0.15 \mathrm{~mol} \mathrm{dm}^{-3} \mathrm{NaOH}$ is presented in Fig. 7. A cathodic photocurrent is observed for potentials of $0.0 \mathrm{~V} /(\mathrm{Ag} \mid \mathrm{AgCl})$ and lower. This is consistent with the composite acting as a p-type material under forward bias. However, as the potential is increased, a small anodic photocurrent is observed and anodic photocurrents in the region of $6.0 \mu \mathrm{A} \mathrm{cm}^{-2}$ are observed at $0.5 \mathrm{~V} /(\mathrm{Ag} \mid \mathrm{AgCl})$ at potentials where the oxidation of glucose is seen (Fig. 2). At these applied potentials, the copper oxide is subjected to extreme reverse bias and under illumination, the photo-generated holes will move to the electrolyte interface. These photo-generated holes are highly oxidizing and could easily promote the oxidation of the adsorbed glucose molecules, as depicted in Eq. (1), or promote the formation of highly reactive hydroxyl radicals, Eq. (2) which

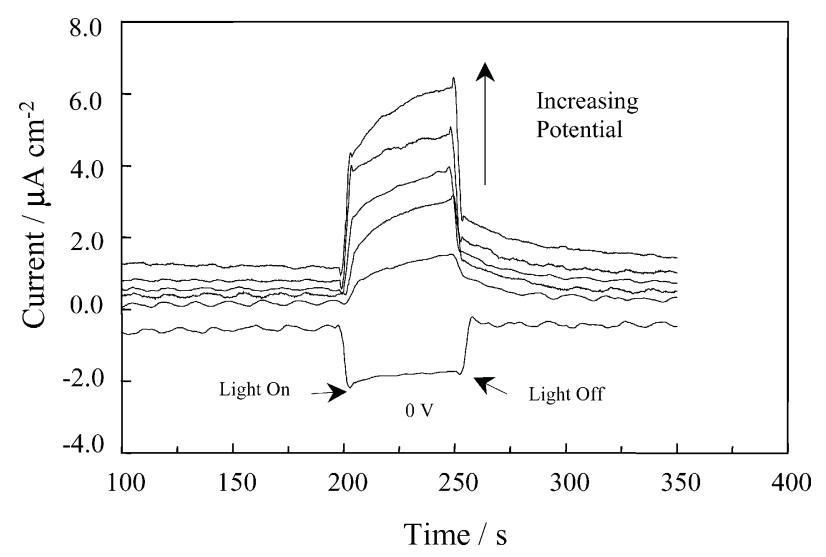

Fig. 7. Photo-response of copper-modified polyaniline electrode at $0,0.1$, $0.2,0.3,0.4$ and $0.5 \mathrm{~V} /(\mathrm{Ag} \mid \mathrm{AgCl})$ in $0.15 \mathrm{~mol} \mathrm{dm}^{-3} \mathrm{NaOH}$. 
then could give rise to the oxidation of the adsorbed glucose at the copper surface. Another potential reaction is the oxidation of $\mathrm{Cu}(\mathrm{I})$ to $\mathrm{Cu}(\mathrm{II})$ by the photo-generated holes, as depicted in Eq. (3). The redox potential of this reaction falls well within the bandgap energy of $\mathrm{Cu}_{2} \mathrm{O}$ [32] making it a thermodynamically viable reaction. Although this production of higher oxidation states of the copper oxides would be an attractive explanation to account for the enhanced oxidation of glucose and related compounds, we could find no electrochemical evidence for a reduction in the amount of $\mathrm{Cu}(\mathrm{I})$ or an increase in the amount of $\mathrm{Cu}(\mathrm{II})$ oxides following illumination, either in the absence or presence of glucose. This was deduced by comparing the charges for the copper oxide reduction peaks, as shown in Fig. 1, following the series of dark or light experiments:

$$
\begin{aligned}
& \text { Glucose }_{\text {solution }} \rightarrow \text { Glucose }_{\mathrm{ads}}+\mathrm{h}^{+} \\
& \rightarrow \text { Intermediates } \rightarrow \text { Formate } \\
& \mathrm{h}^{+}+\mathrm{OH}^{-} \rightarrow \mathrm{OH}^{\bullet} \\
& \mathrm{Cu}_{2} \mathrm{O}+\mathrm{H}_{2} \mathrm{O}+2 \mathrm{~h}^{+} \rightarrow 2 \mathrm{CuO}+2 \mathrm{H}^{+}
\end{aligned}
$$

These photo-induced reactions are not observed at the gold electrode under illumination conditions, Table 1, as the gold oxide is not photoactive.

\section{Conclusion}

The oxidation of glucose was observed between 0.2 and $0.75 \mathrm{~V} /(\mathrm{Ag} \mid \mathrm{AgCl})$ at a copper-dispersed polyaniline electrode. On irradiation of the composite with polychromatic UV light an increase in the rate of the glucose oxidation reaction was observed. These results are explained in terms of the generation of electron-hole pairs on irradiation of the semiconducting copper oxide, with the holes facilitating the oxidation of glucose adsorbed at the copper oxide interface.

\section{Acknowledgements}

Farrell acknowledges the support of the National University of Ireland Maynooth in providing her with a Daniel O’Connell Postgraduate Fellowship and Enterprise Ireland for the provision of a scholarship.

\section{References}

[1] V. Tsakova, D. Borissov, Electrochem. Commun. 2 (2000) 511.

[2] A. Zouaoui, O. Stephan, M. Carrier, J.C. Moutet, J. Electroanal. Chem. 474 (1999) 113.

[3] M.R. Guascito, P. Boffi, C. Malitesta, L. Sabbatini, P.G. Zambonin, Mater. Chem. Phys. 44 (1996) 17.

[4] I. Becerik, F. Kadirgan, J. Electroanal. Chem. 436 (1997) 189.

[5] D. Schroer, R.J. Nichols, H. Meyer, Electrochim. Acta 40 (1995) 1487.

[6] E.C. Venancio, W.T. Napporn, A.J. Motheo, Electrochim. Acta 47 (9) (2002) 1495.

[7] M.C. Henry, C.C. Hsueh, B.P. Timko, M.S. Freund, J. Electrochem. Soc. 148 (2001) D155.

[8] Y.M. Zhu, C.R. Cabrera, Electrochem. Solid State Lett. 4 (2001) A45.

[9] M.J. Croissant, T. Napporn, J.M. Leger, C. Lamy, Electrochim. Acta 43 (1998) 2447.

[10] D.E. Stilwell, S.M. Park, J. Electrochem. Soc. 135 (1988) 2497.

[11] I.G. Casella, T.R.I. Cataldi, A. Guerrieri, E. Desimoni, Anal. Chim. Acta 335 (1996) 217.

[12] I. Becerik, S. Suzer, F. Kadirgan, J. Electroanal. Chem. 476 (1999) 171.

[13] I.G. Casella, M. Gatta, J. Electrochem. Soc. 149 (2002) B465.

[14] S.I. Mho, D.C. Johnson, J. Electroanal. Chem. 500 (2001) 524.

[15] I.H. Yeo, D.C. Johnson, J. Electroanal. Chem. 484 (2000) 157.

[16] N. Torto, T. Ruzgas, L. Gorton, J. Electroanal. Chem. 464 (1999) 252.

[17] T.Y. You, O. Niwa, M. Tomita, H. Ando, M. Suzuki, S. Hirono, Electrochem. Commun. 4 (5) (2002) 468.

[18] Y.B. Vassilyev, O.A. Khazova, N.N. Nikolaeva, J. Electroanal. Chem. 196 (1985) 127.

[19] M.Z. Luo, R.P. Baldwin, J. Electroanal. Chem. 387 (1995) 87.

[20] J.M. Marioli, T. Kuwana, Electrochim. Acta 37 (7) (1992) 1187.

[21] A. Vogel, Textbook of Practical Organic Chemistry, Wiley, 1978 p. 1225.

[22] H.N. Dinh, J. Ding, S.J. Xia, V.I. Birss, J. Electroanal. Chem. 459 (1) (1998) 45.

[23] L.D. Burke, G.M. Bruton, J.A. Collins, Electrochim. Acta 44 (8-9) (1998) 1467.

[24] G.M. Brisard, J.D. Rudnicki, F. McLarnon, E.J. Cairns, Electrochim. Acta 40 (7) (1995) 859.

[25] J.M.M. Droog, C.A. Alderliesten, P.T. Alderliesten, G.A. Bootsma, J. Electroanal. Chem. 111 (1) (1980) 61.

[26] L. Nyholm, L.M. Peter, J. Chem. Soc. Faraday Trans. 90 (1) (1994) 149.

[27] I. Becerik, F. Kadirgan, Electrochim. Acta 37 (14) (1992) 2651.

[28] C.H. Pyun, S.M. Park, J. Electrochem. Soc. 133 (1986) 2024.

[29] L.D. Burke, M.J.G. Ahern, T.G. Ryan, J. Electrochem. Soc. 137 (1990) 553.

[30] K.L. Hardee, A.J. Bard, J. Electrochem. Soc. 124 (1977) 215.

[31] J.B. Goodenough, in: H. Reiss (Ed.), Solid State Chemistry, Pergamon Press, New York, 1971, p. 5.

[32] H. Gerischer, Corros. Sci. 29 (2/3) (1989) 257. 